while $E$ remains constant in the ring considered. This will decrease the losses due to the multipactor effect even more.

We wish to thank the Inter-University Institute for Nuclear Sciences (Belgium), which sponsored this work.

Natuurkundig Laboratorium,

$$
\text { V. J. VANHUYSE }
$$

Rijksuniversiteit,

Ghent, Belgium.

${ }^{2}$ Shersby-Harvie, R. B. R., and Mullett, L. B., Proc. Phys. Soc., B' 62, $270(1949)$

s Miller, C. W., and Saxon, G., Nature, 172, 1163 (1953).

${ }^{2}$ Yfullett, L. 13., Clay, R. E., and Hadden, R. J. B., A.E.R.E. $G R / R$ 1076 (1953).

4 Fladden, R. J. B., A.E.R.E. G/R 1161 (1953).

\section{A New Method of measuring Susceptibility}

IN recent years simple detectors of weak magnetic fields have become available. Magnetometers using the Hall effect in indium antimonide ${ }^{1}$ or ferrite saturation $^{2}$ are capable of measuring fields of a small fraction of an œersted, and they may be used in a magnetic circuit as detectors of magnetic flux, being analogous to a galvanometer detecting current in an electric circuit.

Using this principle, we have built the magnetic analogue of a Wheatstone bridge, with a permanent magnet as the source of magnetomotive force (Fig. 1). The magnetic detector $(D)$ will register no flux when the reluctances of the four air gaps in the soft iron bridge circuit are equal, since the magnetic potentials at $A$ and $B$ will then be the same. If the reluctance of one gap is changed by inserting a sample with a permeability different from that of air, the bridge will become unbalanced and the detector will indicate the magnetic flux passing through it. The bridge may be initially balanced by moving a ferromagnetic screw in one of the gaps.

With gaps of $5-\mathrm{mm}$. length and $0 \cdot 5-\mathrm{cm}^{2}$ crosssectional area, and an M2021 Mullard 'Ticonal' magnet, a field of 1,500 œrsted is obtained in each gap. An InSb magnetometer unit, used in conjunction with a transistor oscillator and amplifier, can detect a field of $10^{-4}$ cersted (Hilsum, C., and 'Thompson, N. A. C., unpublished work). Ideally, therefore, it should be possible to detect a departure from unit permeability by about one part in $10^{7}$, that is, a susceptibility of $10^{-8}$ C.G.s. units.

The performance of an actual instrument is illustrated in Fig. 2. Measurements were made on aqueous solutions of nickel chloride the susceptibilities of which were calculated from the formula given by Nettleton and Sugden ${ }^{3}$. The calibration is essentially

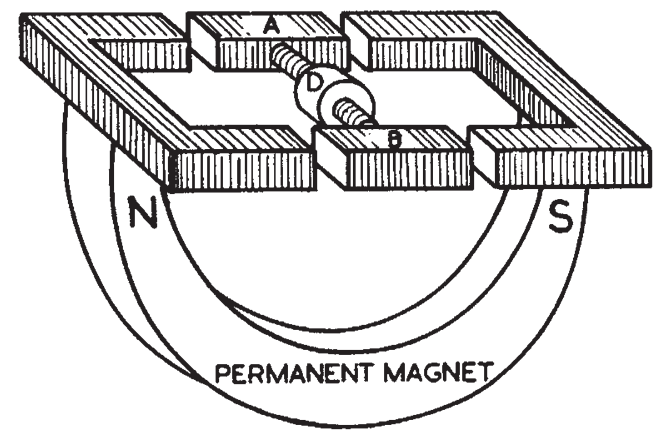

Fig. 1. The magnetic 'Wheatstone bridge'

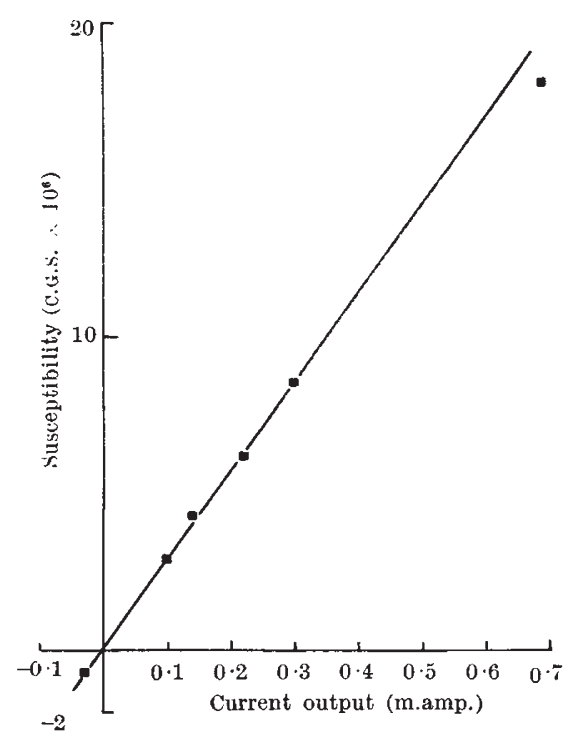

Fig. 2. Calibration curve of susceptibility meter

linear, and the instrument is quite capable of measuring diamagnetic susceptibilities such as that of deionized water. Our apparatus consists of two small boxes, about 8 -in. cube, one of mumetal containing the bridge, and the other for the display meter and the electronics, which operate from a small internal dry battery.

The instrument has the advantages over the usual susceptibility balance of being portable, unaffected by vibration and needing no external power supplies. It is, however, sensitive to variations in the local magnetic field, and measurements cannot be made while ferromagnetic objects are being moved near it. We have found the instrument to be very convenient for use both in the laboratory and in the open. A more detailed account will be given elsewhere.

We are grateful to the Admiralty for permission to publish this communication.

C. Hrisum

A. C. Rose-Innes

Services Electronics Research Laboratory, Baldock, Herts. Sept. 15.

1 Ross, I. M., Saker, E. W., and Thompson, N. A. C., J. Sci. Instr., 34, 479 (1957).

${ }^{2}$ Montague, B. W., Mullard Tech. Comm. 2, 64 (1955).

${ }^{3}$ Nettleton, H. R., and Sugden, S., Proc. Roy. Soc., A, 173, 321 (1939).

\section{Helium in Natural Gas in the Witwatersrand}

DurrNg a visit to the Union of South Africa in the spring of $1957 \mathrm{I}$ observed escapes of natural gas associated with faults and fissures in the underground workings of some of the gold-uranium mines of the Witwatersrand.

It seemed likely that as these major structures cut the uranium-bearing conglomerate horizons, the gas might contain appreciable quantities of helium. Arrangements were therefore made with Dr. J. J. Marais of the Anglo-Transvaal Consolidated Investment Co., Ltd., for a sample of gas to be collected from the Virginia Mine. This material has been analysed chemically and by mass-spectrometry. The results are shown in Table 1.

The high content of helium is of particular interest as the study of its distribution is likelv to throw new 